\title{
Dynamics of Growth, Poverty, and Inequality in Pakistan
}

\author{
SALMAN SYED ALI and SAYYID TAHIR
}

\section{INTRODUCTION}

The relationship between growth, inequality, and poverty has been a moot point. On the one hand growth is considered central or the best course to reduce poverty (e.g. World Development Report 1990) with the preconditions that access to education, health, and social services are available to all by means of other policies. On the other hand, there is a realisation that growth, inequality, and poverty relations are non-linear, complex, and path dependent in their dynamics. An important point made in this context by Kuznets (1955) was the empirical finding of an inverted U (arch) shape relationship between growth and inequality which suggested that the inequality would increase with growth in the beginning, but will decline at higher levels of growth as the benefits of growth trickle down to lower income strata. This argument has been debated since then in the literature with empirical support gathered for and against this hypothesis. Recent theoretical literature on the issue tries to find the micro-foundations of the dynamical relations between these three variables (see for example, proceedings of the 5th ABCDE Annual (World) Bank Conference on Development Economics).

Institutional factors do not change in a few years while they matter in the reduction of poverty as well as in sustaining it at low levels. Hence these relationships are likely to be non-linearity and path dependent, i.e., history matters in the determination of the impact of growth on poverty, of growth on inequality, of inequality on poverty etc. Therefore an understanding of these relationships require knowledge of both the short-run as well as the long-run elasticities of poverty. The method developed by Kakwani (1993) and Kanbur (1987), make use of single survey and provides information on the short-term elasticities but remain silent about longer term relationships between poverty, growth, and inequality. Moreover, it relies on

Salman Syed Ali and Sayyid Tahir are Assistant Professor and Professor at the International Institute of Islamic Economics, International Islamic University, Islamabad.

Authors' Note: This is a slightly abridged version of the actual paper presented in the 15th Annual General Meeting and Conference of PSDE, 5th-8th November 1999. Details can be found in the conference paper circulated in the working paper format or in a companion paper Tahir and Ali (1999). 
restrictive assumptions about the statistical properties of income distribution. Yet another and potentially better approach that does not rely on many statistical assumptions is the decomposition of inter-temporal poverty changes into that due to growth and that due to distribution, suggested by Datt and Ravallion (1992). But again it provides information on short-term elasticities relying on two or a few surveys.

It is partially due to dearth of long time series poverty data, with the exceptions of countries like US and India, that most studies tracing relationships between poverty, inequality and growth using large number of Household Expenditure Surveys were based on international cross-country data in which country specific effects could not be controlled.

The present study attempts to overcome this shortcoming. This paper will analyse the long-run relationships between growth, poverty, and inequality in the context of Pakistan by first obtaining a consistent time series on poverty measures for all Household Income and Expenditure Surveys (HIES) from 1963-64 to 1994-95 (14 of them). In the previous literature on Pakistan, with the exception of Amjad and Kemal (1997), researchers have dealt with data from few survey years and each one has used a different poverty line. This paper does not define a new poverty threshold, it uses the income poverty line defined in Malik (1988) as a benchmark and adjusts it according to inflation before calculating consistent time series for poverty divided into rural and urban sectors as well as the aggregate of the two. For inequality measures the paper relies on the data provided in Mahmood (1984) and Pakistan (Various Issues). Then it directly goes to analysis of inter-relationships between them using regression and event history methods. The consistent time series on rural, urban, and total poverty that this paper develops (using only 14 surveys) is not very large but pooling the data makes it 28 observations and provides a good assessment of long-term growth and inequality elasticities of poverty for a single country (Pakistan) thus providing a control for problems of cross-sectional data. It also provides an opportunity to compare the differences in elasticities of the rural and urban sectors

\section{MEASUREMENT OF POVERTY AND ANALYSIS OF TREND}

\section{Absolute Poverty in Pakistan-A Review of the Literature}

There have been a number of studies on the measurement of poverty in Pakistan. They differ in their definition of the poverty line, the time period covered, the level of disaggregation allowed, regional coverage and unit of analysisindividual or household. There are three approaches in the definition of the poverty line. The first approach arbitrarily specifies a monetary amount as poverty line. For example, income below which 20 percent of the people lie (sometimes referred in the literature as relative poverty). The second approach follows a more systematic quasi-objective approach. In this category two further sub-divisions are possible. 
These sub-divisions can be termed as: (i) The calories-based approach. It involves fixation of minimum calorie intake, selection of food basket which yields the minimum calories, conversion of this basket into a monetary equivalent to arrive at a poverty line.-The poverty line represents the expenditure (or sometimes income) needed to meet the minimum calorie intake. Naseem (1977) is an example of this approach. A variant of this approach emphasises that apart from nutritional needs, non-food expenditures - such as clothing, shelter, etc. - are also critical from the poverty point of view. Malik (1988) follows this approach. (ii) The basic needs approach. According to this approach poverty line is set at the expenditure (or income) needed to meet the minimum requirements of all basic needs, food as well as non-food. Ahmad (1993) estimated minimum requirements on basic needs through holding discussions with professional economists and re-checking with heads of different families, regarding the quantum and value of each of the basic needs. World Bank (1995) adopted several modifications to Ahmad's estimates to arrive at their reference poverty line.

In addition to the foregoing, the third approach, followed by Ali (1997), recommends a total approach in the context of a minimum standard of living. More specifically, Ali uses an Extended Linear Expenditure System to define subsistence expenditure on all consumption items, without reference to calories and composition of the food basket. The poverty line thus arrived at essentially defines a minimum standard of living consistent with the presumed structure of preferences. Results and methods of the various studies are discussed at length in almost all writings on the subject. Therefore we skip the details, except for showing the poverty trends discernible from these studies in Table 1, and refer the reader to two recent studiesAmjad and Kemal (1997), Jafri (1999) — among many others It is obvious that the choice of poverty line affects quantification of poverty in these studies, and not all approaches yield identical pattern of change in poverty over time.

\section{A Consistent Time-series on Trends in Poverty}

A correct assessment of poverty is essential for any further analysis. This paper relies on the consistent data series on household count index and head count index developed in Tahir and Ali (1999). The poverty estimates in this study are based on both food and non-food poverty. In this study Malik (1988)'s estimates of poverty lines for rural and urban areas for 1984-85 are taken as the bench mark. Then, as in Malik (1988) and Amjad and Kemal (1997), poverty lines for other years are obtained by adjusting the above poverty lines with the CPI estimates for those years And, again as in Malik (1988), Mujahid (1978)'s methodology is used to arrive at the poverty estimates. Poverty is primarily estimated in terms of the head-counts in total population, but the household counts are also made in order to facilitate comparison with the income inequality data. Throughout we have relied on primary data either in grouped (i.e., tabulated) form or in individual (micro level) 
Table 1

The Existing Evidence on Trends in Poverty

\begin{tabular}{|c|c|c|c|c|c|c|}
\hline & Study & Overall & Rural & Urban & Data Points & Poverty Line/Unit \\
\hline & & \multicolumn{5}{|c|}{ Poverty in the Sixties } \\
\hline 1. & Naseem (1973) & - & Decline & Decline & $\begin{array}{l}1963-64,1966-67 \\
1968-69,1969-70\end{array}$ & $\begin{array}{l}\text { Per capita expenditure; } \\
\text { Percent of households }\end{array}$ \\
\hline 2. & Allaudin (1975) & - & Decline & Decline & Same as above. & $\begin{array}{l}\text { Per capita income; } \\
\text { Percent of households }\end{array}$ \\
\hline 3. & Naseem (1977) & - & Increase & - & $\begin{array}{l}1963-64,1966-67 \\
1968-69,1969-70\end{array}$ & $\begin{array}{l}95 \%, 92 \%, 90 \% \text { of } \\
2100 \text { calories }\end{array}$ \\
\hline 4. & Mujahid (1978) & - & Increase & Decline & Same as above. & $\begin{array}{l}\text { Per capita expenditure; } \\
\text { Percent of households }\end{array}$ \\
\hline 5. & $\begin{array}{l}\text { Irfan and Amjad } \\
(1984)\end{array}$ & - & Increase & - & $\begin{array}{l}\text { Same as above, } \\
\text { except 1968-69 }\end{array}$ & 2550 calories \\
\hline 6. & Malik (1988) & Increase & Increase & Decline & $\begin{array}{l}\text { Same as above, } \\
\text { except } 1968-69\end{array}$ & $\begin{array}{l}\text { Per capita } \\
\text { expenditure }(2500 \\
\text { calories }+ \text { non-food }) \text {; }\end{array}$ \\
\hline \multirow[t]{2}{*}{7.} & $\begin{array}{l}\text { Amjad and Kemal } \\
\text { (1997) }\end{array}$ & Increase & Increase & Decline & $\begin{array}{l}\text { Same as Malik } \\
(1988)\end{array}$ & Same as above \\
\hline & & \multicolumn{5}{|c|}{ Poverty in the Seventies } \\
\hline 1. & $\begin{array}{l}\text { Irfan and Amjad } \\
\text { (1984) }\end{array}$ & - & Decline & - & $1969-70,1979$ & $\begin{array}{l}2550 \text { calories; } \\
\text { Percent of population }\end{array}$ \\
\hline 2. & Malik (1988) & Decline & Decline & Decline & Same as above. & $\begin{array}{l}\text { Same as Malik (1988) } \\
\text { above }\end{array}$ \\
\hline 3. & $\begin{array}{l}\text { Kruijik and van } \\
\text { Leewin (1985) }\end{array}$ & Decline & Decline & Decline & Same as above. & $\begin{array}{l}\text { Monthly expenditure } \\
\text { of Rs } 700 \text { at } 1979 \\
\text { prices; Percent of } \\
\text { households }\end{array}$ \\
\hline \multirow[t]{3}{*}{4.} & Ali (1997) & Increase & & & $1969-70,1979$ & $\begin{array}{l}\text { Utility function-based } \\
\text { concept of poverty }\end{array}$ \\
\hline & $\begin{array}{l}\text { Amjad and Kemal } \\
\text { (1997) }\end{array}$ & Decline & Decline & Decline & $1969-70,1979$ & Same as Malik (1988) \\
\hline & & \multicolumn{5}{|c|}{ Poverty in the Eighties and Thereafter } \\
\hline 1. & Malik (1988) & Decline & Decline & Decline & $1979,1984-85$ & $\begin{array}{l}\text { Same as Malik (1988) } \\
\text { above }\end{array}$ \\
\hline 2. & Shirazi (1995) & Increase & Increase & Increase & $1987-88.1990-91$ & $\begin{array}{l}\text { Basket of basic needs; } \\
\text { Percent of population }\end{array}$ \\
\hline 3. & Malik (1996) & Decline & Decline & Decline & $1984-85,1987-88$ & 2550 calories; \\
\hline & & Increase & Increase & Increase & $1987-88,1990-91$ & Percent of population \\
\hline 4. & $\begin{array}{l}\text { Gazdar et al. } \\
\text { (1994) }\end{array}$ & $\begin{array}{l}\text { Decline } \\
\text { Decline }\end{array}$ & $\begin{array}{l}\text { Decline } \\
\text { Decline }\end{array}$ & $\begin{array}{l}\text { Decline } \\
\text { Decline }\end{array}$ & $\begin{array}{l}1984-85,1987-88 \\
1987-88,1990-91\end{array}$ & $\begin{array}{l}\text { Basket of basic needs; } \\
\text { Percent of population }\end{array}$ \\
\hline 5. & Ali (1997) & Increase & & & $\begin{array}{l}1984-85,1987-88 \\
1990-91\end{array}$ & $\begin{array}{l}\text { Same as Ali (1997) } \\
\text { above }\end{array}$ \\
\hline 6. & $\begin{array}{l}\text { Amjad and Kemal } \\
\text { (1997) }\end{array}$ & Decline & Decline & Decline & $\begin{array}{l}1979,1984-85 \\
1987-88\end{array}$ & Same as Malik (1988) \\
\hline & & Increase & Increase & Increase & $1990-91,1992-93$ & \\
\hline 7. & Jafri (1999) & Decline & Decline & Decline & $1990-91$ & \\
\hline & & $\begin{array}{l}\text { Increase } \\
\text { Increase }\end{array}$ & $\begin{array}{l}\text { Decline } \\
\text { Increase }\end{array}$ & $\begin{array}{l}\text { Increase } \\
\text { Decline }\end{array}$ & $\begin{array}{l}1992-93 \\
1993-94\end{array}$ & $\begin{array}{l}\text { Basic needs based on } \\
\text { expenditure }\end{array}$ \\
\hline
\end{tabular}

Notes: 1. Malik (1996) used a 2550 per adult equivalent calories-based poverty line calculated by regressing caloric intake against total expenditure.

2. Ali (1997)'s results are due to fixing the poverty lines at very high levels. 
form using Household Income and Expenditure Surveys for calculation of poverty and other variables. No secondary estimates are used. The details of the procedure and how this data set is better than other studies on Pakistan, in terms of its coverage and consistency, can be found in Tahir and Ali (1999).

This consistent time-series on poverty, defined in terms of household-count index, and a consistent time series on individual head-count are given in Table 2.

Table 2

Consistent Time Series on Poverty Statistics for Pakistan

\begin{tabular}{|c|c|c|c|c|c|c|}
\hline \multirow[b]{2}{*}{ (1) } & \multicolumn{3}{|c|}{$\begin{array}{l}\text { Household Count Index* } \\
\text { (Percentage) }\end{array}$} & \multicolumn{3}{|c|}{$\begin{array}{l}\text { Head Count Index } * *, * * * \\
\text { (Percentage) }\end{array}$} \\
\hline & (2) & (3) & (4) & (5) & (6) & (7) \\
\hline Period & Rural & Urban & Total & Rural & Urban & Total \\
\hline $1963-64$ & 37.36 & 41.46 & 39.18 & 39.57 & 45.1 & 40.84 \\
\hline & & & & (Rs 26.44) & (Rs 30.77) & \\
\hline $1966-67$ & 45.29 & 35.74 & 39.35 & $\begin{array}{r}46.94 \\
\text { (Rs } 30.85 \text { ) }\end{array}$ & $\begin{array}{r}39.22 \\
\text { (Rs } 35.90)\end{array}$ & 45.09 \\
\hline $1968-69$ & 45.61 & 36.72 & 42.50 & $\begin{array}{r}49.70 \\
\text { (Rs } 32.46 \text { ) }\end{array}$ & $\begin{array}{r}40.92 \\
\text { (Rs } 37.77 \text { ) }\end{array}$ & 47.59 \\
\hline $1969-70$ & 44.98 & 34.71 & 38.63 & $\begin{array}{r}49.92 \\
\text { (Rs 33.80) }\end{array}$ & $\begin{array}{r}39.52 \\
\text { (Rs 39.32) }\end{array}$ & 47.32 \\
\hline $1970-71$ & 46.37 & 37.31 & 40.81 & $\begin{array}{r}51.32 \\
\text { (Rs 36.64) }\end{array}$ & $\begin{array}{r}42.55 \\
\text { (Rs 42.63) }\end{array}$ & 49.13 \\
\hline $1971-72$ & 49.62 & 35.33 & 40.76 & $\begin{array}{r}53.35 \\
\text { (Rs } 37.41)\end{array}$ & $\begin{array}{r}39.37 \\
\text { (Rs } 43.53 \text { ) }\end{array}$ & 49.85 \\
\hline 1979 & 27.71 & 22.31 & 25.66 & $\begin{array}{r}30.93 \\
\text { (Rs } 96 . .96)\end{array}$ & $\begin{array}{r}24.57 \\
\text { (Rs } 112.81)\end{array}$ & 29.15 \\
\hline $1984-85$ & 24.10 & 19.40 & 22.79 & $\begin{array}{r}25.87 \\
(\text { Rs } 159.00)\end{array}$ & $\begin{array}{r}21.17 \\
\text { (Rs } 185.00)\end{array}$ & 24.46 \\
\hline $1985-86$ & 20.74 & 18.17 & 19.58 & $\begin{array}{r}22.20 \\
(\operatorname{Rs~} 165.90)\end{array}$ & $\begin{array}{r}19.36 \\
\text { (Rs 193.10) }\end{array}$ & 21.35 \\
\hline $1986-87$ & 18.14 & 15.61 & 17.00 & $\begin{array}{r}19.43 \\
\text { (Rs } 171.90)\end{array}$ & $\begin{array}{r}16.86 \\
\text { (Rs 200.00) }\end{array}$ & 18.65 \\
\hline $1987-88$ & 18.24 & 14.93 & 16.72 & $\begin{array}{r}20.36 \\
\text { (Rs } 182.71)\end{array}$ & $\begin{array}{r}16.56 \\
\text { (Rs 212.59) }\end{array}$ & 19.18 \\
\hline $1990-91$ & 23.46 & 18.70 & 21.41 & $\begin{array}{r}24.49 \\
\text { (Rs 240.95) }\end{array}$ & $\begin{array}{r}19.82 \\
(\text { Rs 280.35) }\end{array}$ & 23.00 \\
\hline $1992-93$ & 27.41 & 19.77 & 24.48 & $\begin{array}{r}30.53 \\
\text { (Rs 288.57) }\end{array}$ & $\begin{array}{c}22.91 \\
\text { (Rs 335.76) }\end{array}$ & 28.11 \\
\hline 1993-94 & 27.88 & 17.57 & 23.92 & $\begin{array}{r}31.24 \\
\text { (Rs 320.82) }\end{array}$ & $\begin{array}{r}20.89 \\
\text { (Rs } 373.28 \text { ) }\end{array}$ & 27.93 \\
\hline
\end{tabular}

Notes: * Household-count index gives the percentage of households below the household poverty line (not shown above). The estimates in column (4) are weighted averages of those in columns (2) and (3).

** Head-count index gives the percentage of population below the poverty line. The estimates in column (7) are weighted averages of those in columns (5) and (6).

*** Per capita poverty lines for rural and urban areas, at current prices, are shown in the parentheses below the respective head-count indices. 


\section{MEASUREMENT OF INEQUALITY AND ANALYSIS OF TREND}

Income inequality in Pakistan is studied in terms of the conventional measures of Gini coefficient, Thile index, and the ratio of income shares of the highest 20 percent to the lowest 20 percent of primary units. Generally the primary unit of analysis had been households instead of individuals. Data on these inequality measures at household level is available in Pakistan Economic Survey at the national, rural and urban classification. Data on rural and urban Gini coefficients for period before 1979 is in Mahmood (1984). Because Gini coefficient is more sensitive to changes in the middle than to changes in the tail of income distribution we supplement the analysis of income distribution with the ratio of income shares of the lowest to the highest 20 percent of households and where possible with Thile index. Thile index has the advantage that it is relatively more sensitive to changes in the tails of the distribution as well as it is decomposable (i.e., in our case decomposition of total into rural and urban components) while Gini is not.

The data reveals that income inequality as measured by Gini coefficient declined during the sixties, increased in the seventies, decreased during the eighties but again increased from 1987-88 onwards. This evidence is corroborated by a similar movement of the ratio of income shares. Urban income inequality in terms of Gini coefficient has been consistently higher than the rural inequality until 1990-91 and lower thereafter.

When we look at the income shares of the lowest 20 percent of households we find that the lowest 20 percent of the rural household has higher share of rural income than the share of lowest 20 percent of the urban household in the urban income. Similarly, the highest 20 percent of household in the urban sector has consistently possessed higher share of the urban income than the similar group in rural areas. This indicates that the switch over in the Gini coefficient is due to change in the income distribution at the middle income group.

The causes of these trends have been numerous such as the ones identified by Naseem (1996) that include: for the drop in overall inequality between 1963-64 to 1971-72 - the impact of green revolution; for increase between 1971-72 to mideighties - adverse change in the agrarian structure due to ineffective land reforms; for increase in rural inequality after 1986-87 - structural adjustment programmes that included increase in exchange rate, removal of subsidies higher output prices for the major crops that have benefited the large farmers And for persistently higher urban inequality - the rural to urban migration etc.

\section{MEASUREMENT OF GROWTH}

Traditionally growth has been measured in terms of per capita income. This statistic is not obtained from the HIES data but calculated from the estimates of GNP and population. For consistency of our analysis and validity of our statistical procedure (more on this in later sections) we required a more direct measure of 
growth based on the same sample survey from which other measures of poverty and inequality are derived. So we have settled for average household income as an indicator of growth and reported it in Table 3.

Table 3

Average Household Income (in Rupees)

\begin{tabular}{lccc}
\hline Year & Rural & Urban & Total \\
\hline $1963-64$ & 193 & 236 & 203 \\
$1966-67$ & 198 & 281 & 219 \\
$1968-69$ & 190 & 293 & 215 \\
$1969-70$ & 197 & 303 & 223 \\
$1970-71$ & 209 & 317 & 235 \\
$1971-72$ & 234 & 361 & 265 \\
1979 & 836 & 1346 & 1032 \\
$1984-85$ & 1538 & 2390 & 1774 \\
$1985-86$ & 1638 & 2537 & 1889 \\
$1986-87$ & 1775 & 2739 & 2062 \\
$1987-88$ & 1815 & 2956 & 2131 \\
$1990-91$ & 2961 & 3701 & 3168 \\
$1992-93$ & 3070 & 4976 & 3590 \\
$1993-94$ & 3073 & 5325 & 3960 \\
\hline
\end{tabular}

\section{RELATION BETWEEN GROWTH AND ABSOLUTE POVERTY}

Economic growth can be an effective anti-poverty tool. But the extent to which growth benefits the poor depends upon a number of factors that have to do with the channels through which fruits of growth are distributed in the economy. Pakistan's experience is that economic growth has not translated into poverty reduction in all periods. Indeed increase in real per capita income has been a dominant source of reduction in poverty in the late seventies and throughout the eighties, but this was not the case in the sixties. During that period in spite of rise in per capita income and decline in inequality poverty increased both in the urban and rural areas, and the rise in rural poverty far exceeded the rise in urban poverty. There can be a number of causes for the above phenomenon. Economic growth accompanied by declining real wages among low-wage workers or reduced employment of unskilled labour or reduction in public assistance are likely causes of relatively small impact of growth on poverty. Economic growth may not result in even growth in all sub-sectors of the economy, and the growth in each sub-sector may not be equally effective in reducing poverty. Growth in the sectors that employ larger proportion of low wage unskilled workers is likely to reduce poverty than growth in the others that utilise skilled labour or are more capital intensive. 
Likewise, differential impact on poverty in rural and urban areas is possible due to the difference of the rural- or urban-based inputs used by the various sectors as well as differences in the nature of economic shocks suffered by the two areas and the insurance mechanisms in place etc. In order to analyse the relation between growth and poverty, we calculated the growth elasticity of demand.

\section{Methods and Issues in the Measurement of Impact of Growth on Poverty}

Kakwani (1993) has developed a methodology to separately measure the impacts of changes in average income and income inequality on poverty by deriving analytical formulae for this purpose. His method of obtaining poverty elasticity of growth, holding inequality constant, has two disadvantages (i) it gives only the point elasticities by use of single survey, and (ii) it requires knowledge of the probability density of income at the poverty threshold, which is not always available. Kakwani was able to derive this density only for a special parametric form of the Lorenz curve by utilising its second derivative under particular assumptions. ${ }^{1}$ Though we noted these difficulties, we have not calculated these point elasticities in this paper. Such an attempt, if at all, can be made only for the HIES data after the mid-eighties that is available in primary form.

Datt and Ravallion (1992) provided another, much simpler, method to decompose change in poverty into growth and inequality components. Their method has the advantage that it does not require any assumptions about the functional form of the Lorenz curve or the probability distribution. Moreover, it is applicable even to discrete changes in poverty between two surveys. But again it provides a measure of short-run relation.

Let us turn now to the issue of estimating long-term poverty elasticity of growth. In the previously mentioned techniques it was not possible to capture the long-run effects. Moreover, in the Kakwani (1993) formulation the short-run effect of growth on poverty was calculated in such a way that possible interaction of growth on inequality, which could subsequently influence poverty, was altogether ignored. A possible way to overcome all these shortcomings is to apply regression methods on our data. One possibility is to use the regression equation of the following form on pooled data for rural and urban areas of Pakistan.

$$
\ln \left(H H C_{a t}^{*}\right)=b_{0}+b_{1} \ln \left(A H H I_{a t}^{*}\right)+b_{a}+\omega_{a t} \quad \ldots \quad \ldots \quad \ldots
$$

Where, $b_{0}=$ fixed effect, $b_{a}=$ area random effect, $b_{1}=$ growth elasticity of poverty, $\omega_{a t}=$ random errors in poverty measure that are iid over time and across rural urban areas.

The second possibility is to use the model with time trend as given in the following equation:

\footnotetext{
${ }^{1}$ For details see Kakwani (1993), p.137.
} 


$$
\ln \left(H H C_{a t}^{*}\right)=\alpha_{a}+\beta_{1} \ln \left(A H H I_{a t}^{*}\right)+\gamma T+\varepsilon_{a t} \quad \ldots \quad \ldots \quad \ldots
$$

Where, $H H C^{*}{ }_{a t}=$ Household Count pooled over time and across rural urban areas, $\mathrm{AHHI}_{\mathrm{at}}{ }^{*}=$ Average Household Income pooled over time and across rural urban areas, $T=$ Time trend (that increases by the number of years lapsed from one survey to the other). Subscripts $a=$ Rural, Urban; and $t=$ time. Coefficients: $\alpha_{a}=$ area fixed effects capturing differences that persist over time between rural urban areas, $\beta=$ growth elasticity of poverty, $\gamma=$ trend rate of change in poverty due to time, $\varepsilon_{a t}=$ errors in poverty measure that are iid over time and between areas.

The third possibility is to take the analysis to a more disaggregate level in relating various sectoral growth rates to poverty, where sectors are such as agriculture, manufacturing, trade, transport, services, etc.

As for the use of models in Equation 1 and Equation 2 above, there are certain advantages of the data and the statistical properties of the model. These are as follows:

(i) We have 14 data points each for rural and urban areas. Pooling them gives us a fairly large sample of 28 data points for one country. A time series analysis of poverty and growth on single country data was previously not possible for developing countries (with India as a rare exception, and recently Bangladesh). A majority of studies attempting to quantify this relation had to rely on cross country data where country specific effects, and hence resultant hetroskedasticity, could not be controlled. The present study is free from this problem and the control over area-specific effects is achieved except for rural urban differences, if they at all exist, within the country.

(ii) In addition to the pooled data, we can analyse the relationships separately for the rural and the urban areas as well as for a weighted average of the two areas. Where weights are proportion of households in the two areas.

(iii) As far as the consistency of data across the surveys, and the choice of estimation technique are concerned, we realise that the observed values of average household income $A H H I_{a t}$, and household count $H H C_{a t}$ may not be the true values - represented by an asterisk $A H H I^{*}{ }_{a t}$ and $H H C^{*}{ }_{a t}$. That is we have, a sort of, errors in the variables problem. It is arising from variation in questionnaires used over time, variations in ways to ask questions, income imputation techniques that have changed over the years, sample size, area of coverage of a survey, variations in time lags from one survey to the next as well as differences in the social-political environments between various surveys that can influence the answers ${ }^{2}$ These factors create problems in

${ }^{2}$ Note that respondents generally under-report their incomes in the HIES data. This kind of consistent error is not at issue here because it can be easily corrected for by revising the numbers upwards once we know the magnitude of the error. It is the randomness in the reporting and measurement errors that are of concern here. 
obtaining consistent estimates of long-run elasticities. But, by taking cognisance of the problem and adopting appropriate approach, these can be controlled much more easily than such problems in the cross country data derived from very different surveys with so many different sources of errors

Assume that the observed values are proxies for true values.

$$
\begin{array}{lllll}
\ln H H C_{a t}=\ln H H C_{a t}^{*}+\mu_{a t} & \ldots & \ldots & \ldots & \ldots \\
\ln A H H I_{a t}=\ln A H H I_{a t}^{*}+v_{a t} & \ldots & \ldots & \ldots & \ldots
\end{array}
$$

Where, $v_{a t}$ is random error term that is iid over time and across rural-urban areas. Note that the errors $\mu_{a t}$ does not pose any problem as these can be absorbed in the error term of poverty, $\omega_{a t}$, in case of Equation 1 ( or in the error term $\varepsilon_{a t}$ in case of Equation 2). It is the errors $v_{a t}$ in $\ln A H H I_{a t}$ that pose a problem of stochastic regressors and rendering the OLS estimates biased and inconsistent. For the purpose of illustration we will derive results with respect to Equation 1, similar results can be obtained for the model in Equation 2. It can be readily seen by substituting Equation 4 in Equation 1.The error term (shown below in the parenthesis) for the resultant equation becomes correlated with the explanatory variable, hence the violation of OLS assumption.

$$
\operatorname{lnHHC}_{a t}=b_{0}+b_{1}\left(\ln A H H I_{a t}\right)+b_{\alpha}+\left(\varepsilon_{a t}+b_{1} v_{a t}\right) \quad \ldots \quad \ldots
$$

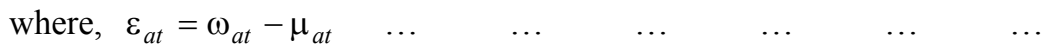

Ravallion and Chen (1997) using cross country data to estimate the relationship between poverty and growth could not control for the country specific effects but they were able to control for the time varying error factor. We will utilise the same argument here which is simple but innovative. According to them, since each pair of data on growth, and poverty variables [in our case $\left.\left(A H H I_{a t}, H H C_{a t}\right)\right]$ are obtained from the same survey, therefore if a survey over (under) estimates average household income than its true value, then estimation of household count presumably will be lower (higher) than its true value. Therefore $\omega_{a t}$ and $v_{a t}$ will be negatively correlated. This along with a simplifying assumption removes the problem of stochastic regressors and OLS method can be applied.

For illustration purpose focus on the model of Equation 1 or its explicit form Equation 5. We know that

$$
\hat{b}_{1}=b_{1}+\frac{\sum_{t}\left\{\left[\ln A H H I_{a t}-E\left(\ln A H H I_{a t}\right)\right]\left(\varepsilon_{a t}-b_{1} v_{a t}\right)\right\}}{\sum_{t}\left[\ln A H H I_{a t}-E\left(\ln A H H I_{a t}\right)\right]^{2}} \quad \ldots
$$


Substituting the expression for $\ln A H H I_{a t}$ from Equation 4 in the numerator and using the fact that $E\left[v_{a t}\right]=0$ and then taking the probability limit we can get

$$
P \lim \hat{b}_{1}=b_{1}+\frac{\left[\operatorname{Cov}\left(v_{a t}, \varepsilon_{a t}\right)-b_{1} \operatorname{Var}\left(v_{a t}\right)\right]}{\operatorname{Var}\left(\ln A H H I_{a t}\right)} \quad \ldots \quad \ldots \quad \ldots
$$

Which shows the bias and hence inconsistency in the estimator.

Note that the growth elasticity of poverty in the regression Equation 2 or 1 is an empirical relationship which captures the direct effect of growth on poverty, and indirect effect of growth via change in income distribution that can work in opposite direction if growth skews income distribution in favour of the rich. The net effect reflected in $b_{1}$ can well be positive or negative depending upon how the income distribution responds to growth. This is in contrast to Kakwani (1993) where growth elasticity of poverty is necessarily negative because income distribution is held constant.

Now if growth in fact reduces poverty, then $b_{1}<0$ which implies that in equation 8 the second term in brackets becomes positive. We have earlier argued for the plausibility of $\operatorname{Cov}\left(v_{a t}, \varepsilon_{a t}\right)<0$. Thus the two numerator terms in Equation 8 work in opposite direction to cancel out the inefficiency bias. If $\operatorname{Cov}\left(v_{a t}, \varepsilon_{a t}\right)$ exactly equals $-b_{1} \operatorname{Var}\left(v_{a t}\right)$ but with opposite sign the second term in above equation is zero and $P \lim \hat{b}_{1}=b_{1}$. What are some minimum restrictions that can generate this equality? It is achieved in Ravallion and Chen (1997) by assuming that

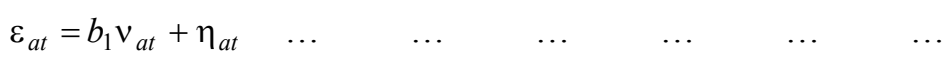

That is, errors in measurement of poverty are partially due to errors in measurement of average household income and partially due to errors in measurement of distribution of income $\eta_{a t}$. In this event Equation 8 becomes

$$
P \lim \hat{b}_{1}=b_{1}+\frac{\left[\operatorname{Cov}\left(v_{a t},\left(b_{1} v_{a t}+\eta_{a t}\right)\right)-b_{1} \operatorname{Var}\left(v_{a t}\right)\right]}{\operatorname{Var}\left(\ln A H H I_{a t}\right)} \quad \ldots \quad \ldots
$$

Using the definition of covariance and the fact that $\bar{v}=\bar{\eta}=0$, we get

$$
P \lim \hat{b}_{1}=b_{1}+\frac{\sum_{t} \operatorname{Cov}\left(v_{a t}, \eta_{a t}\right)}{\operatorname{Var}\left(\ln A H H I_{a t}\right)} \quad \ldots \quad \ldots \quad \ldots \quad \ldots
$$

There is no obvious reason why errors in the measurement of average household income should be correlated with errors in measurement of income distribution. A higher side error in $A H H I_{a t}^{*}$ can be due to over estimation of the income of rich only or poor only or both. Thus $\operatorname{Cov}\left(v_{a t}, \eta_{a t}\right)=0$. Hence,

$\begin{array}{llllllll}P \lim \hat{b}_{1}=b_{1} & \ldots & \ldots & \ldots & \ldots & \ldots & \ldots\end{array}$ 
We can therefore apply OLS and our estimates of $b_{1}$ are going to be unbiased and consistent.

The advantage of our model and data over that of earlier studies using crosscountry studies is obvious. A difference between our approach and that of Chen and Ravallion (1997) is that owing to no country specific effects (or no latent heterogeneity) we can apply the OLS on the levels data. Whereas, the above mentioned authors had to use first difference data for each country with difference taken over two successive surveys for the same year. That process itself changes the error structure of the model and can inadvertently introduce autocorrelation, due to common survey bias, when there was none.

\section{Estimation Results}

The above stated regression Equation 1 gives direct and indirect combined effect of growth on poverty. The growth elasticity of poverty thus obtained at national-pool (28 observations), rural (14 observations), urban (14 observations), and country weighted (14 observations) levels for Equation 1 are shown in Table 4. It shows that a 1 percent increase in average household income reduces poverty (household count) by 0.291 percent in the urban areas, and it brings out of poverty slightly smaller proportion of households, 0.266 percent, in the rural areas. In the country weighted data this elasticity is -0.256 while in the national pooled data it is slightly higher at -0.286 .

Table 4

Results of Regression of Poverty on Growth

Dependent variable: Log Household Count Independent

Variables: Log Average Household Income $\ln H H C_{a t}=b_{0}+b_{1} \ln \left(A H H I_{a t}\right)+b_{a}$

\begin{tabular}{lcccc} 
& Rural & Urban & National Pooled & National Weighted \\
\hline $\mathrm{b}_{0}$ & 5.18 & 5.24 & 5.26 & 5.05 \\
& $(7.630)$ & $(13.50)$ & $(16.35)$ & $(8.27)$ \\
$\mathrm{b}_{1}$ & -0.266 & -0.29 & -0.29 & -0.256 \\
& $(-3.20)$ & $(-5.38)$ & $(-5.90)$ & $(-3.02)$ \\
Adj. ${ }^{2}$ & 0.76 & 0.91 & 0.82 & 0.79 \\
D.W. & 1.33 & 1.43 & 1.34 & 1.28 \\
$\mathrm{~F}$ & 28.86 & 58.8 & 92.8 & 34.6 \\
$\rho$ & 0.69 & 0.5 & 0.62 & 0.7 \\
\hline
\end{tabular}

It was also thought that some change in poverty may be explainable by many other time dependent factors that are not captured due to uneven time lags between the surveys, therefore an estimate with a time trend is also made using Equation 2 
and results reported in Table 5. (The time trend here adds the number of years lapsed between successive surveys). This formulation gives the income elasticity of poverty in the urban areas -0.52 which is lower than the elasticity of -0.77 in the rural areas. This elasticity is -0.59 and -0.55 in the national pooled data, and the country weighted average data respectively.

Table 5

Regression of Poverty on Growth with Time Trend

Dependent Variable: log Household Count Independent Variables: log (Average Household Income)

Time Trend

\begin{tabular}{|c|c|c|c|c|}
\hline & \multirow{2}{*}{\multicolumn{4}{|c|}{$\begin{array}{c}\ln H H C_{a t}=\alpha_{0}+\beta \ln \left(A H H I_{a t}\right)+\gamma T+A R(1)+\gamma_{a t} \\
\text { Corrected for Serial/Auto-correlation }\end{array}$}} \\
\hline & & & & \\
\hline & Rural & Urban & $\begin{array}{c}\text { National } \\
\text { Pooled }\end{array}$ & $\begin{array}{c}\text { National } \\
\text { Weighted }\end{array}$ \\
\hline$\alpha_{0}$ & $\begin{array}{c}7.59 \\
(4.76)\end{array}$ & $\begin{array}{c}6.39 \\
(5.85)\end{array}$ & $\begin{array}{c}6.75 \\
(16.35) \\
(14.4)\end{array}$ & $\begin{array}{c}6.47 \\
(5.43)\end{array}$ \\
\hline$\beta$ & $\begin{array}{l}-0.77 \\
(-2.05)\end{array}$ & $\begin{array}{l}-0.52 \\
(-2.57)\end{array}$ & $\begin{array}{c}-0.59 \\
(-4.84) \\
(-6.17)\end{array}$ & $\begin{array}{l}-0.55 \\
(-2.09)\end{array}$ \\
\hline$\gamma$ & $\begin{array}{r}0.06^{*} \\
(1.2)\end{array}$ & $\begin{array}{l}0.03 * \\
(1.38)\end{array}$ & $\begin{array}{l}0.04 \\
(2.71) \\
(3.02)\end{array}$ & $\begin{array}{l}0.03^{*} \\
(1.16)\end{array}$ \\
\hline Adj. $R^{2}$ & 0.79 & 0.9 & 0.87 & 0.80 \\
\hline D.W. & 1.41 & 1.45 & $\begin{array}{l}1.38 \\
(2.03)\end{array}$ & 1.25 \\
\hline $\mathrm{F}$ & 20.3 & 44.7 & $\begin{array}{l}81.1 \\
(18.4)\end{array}$ & 24.9 \\
\hline$\rho$ & 0.59 & 0.52 & $\begin{array}{c}0.57 \\
(0.86)\end{array}$ & 0.73 \\
\hline
\end{tabular}

Notes: 1. The coefficients are based on OLS estimation while the $t$-values are in parenthesis, which are based on robust standard errors after correcting for auto-correlation using AR(1) CochraneOrcutt iterative procedure.

2. Coefficients not significant at 5 percent level are marked with an asterisk $(*)$.

3. Adjusted $\mathrm{R}^{2}$ is based on original OLS method, while $F$-Statistic is that after correction for autocorrelation.

4. $\rho$ estimate of auto-correlation coefficient in errors 
Due to the presence of a positive autocorrelation in the estimation errors of Equation 1 and 2, the claim of efficiency of these estimators was not possible except for their unbiasedness. To overcome this problem we applied Cochran-Orcutt iterative method and obtained $t$-values corrected for autocorrelation. The new $t$ statics show the significance of the elasticities at 5 percent level. Note that we are not using the new values of the estimated coefficients (obtained after correction for autocorrelation), except for their new $t$-statistics and $F$-statistic, because interpretation of these GLS estimates thus obtained is not possible easily after the data transformation. By using the old estimates we preserve the elasticity interpretation of the data. The limitation of this approach is that we cannot confidently test the hypothesis that income elasticity of poverty in the urban area is indeed greater than that in the rural areas. ${ }^{3}$ If the quasi-GLS estimators (not reported) are interpreted as coefficients of rate of change and when autocorrelation coefficient $\rho$ is close to unity, then the new estimators show the responsiveness of the rate of poverty change to a unitary change in the growth rate of income.

The autocorrelation that remains may be due to specification bias that can result from a structural break in the poverty series that has come about due to a long period of gap between 1971-72 and 1979 during which no HIES survey was made but poverty dropped considerably between the start and end of this no-information period. A strong conclusion that emerges is that growth measured in terms of the level of average household income or as the rate of change in the average household income reduces poverty in terms of bringing some number of households out of poverty as well as in terms of the rate of this movement out of poverty, both in the rural and urban areas.

\section{RELATION BETWEEN INEQUALITY AND GROWTH}

As mentioned earlier, inequality is expected to be non-linearly influenced by a host of institutional and social factors along with growth. Moreover, the relationship between these two variables is not based only on one way causalitygrowth thereby causing inequality. In the long-run a feedback effect of inequality on growth also exists. These factors make it difficult to obtain a lemph \{universal and empirically consistent $\}$ relationship between inequality and growth. Moreover, difficulties in operationalising the definitions of these variables and lack of information on the time lags with which these variables affect each other make the matter more complicated.

Given the limitations of our data and the above mentioned considerations we are content with smaller objectives which are: (i) to obtain growth elasticities of

\footnotetext{
${ }^{3}$ See Gujarati (1995), pp. 408-411, and pp. 427-433 for details.
} 
inequality postulating a linear relationship and (ii) to find the impact of growth on income disparity. ${ }^{4}$

\section{Income Elasticity of Inequality}

To obtain elasticity we regressed the following equation using the OLS method. The same considerations and econometric justification, as discussed in earlier sections, apply here.

$$
\ln \operatorname{Gini}_{a t}=d_{0}+d_{1} \operatorname{lnAHHI}_{a t}+d_{\alpha}+\xi_{a t} \quad \ldots \quad \ldots \quad \ldots
$$

Where the dependent variable is $\log$ of Gini coefficient and subscripts $a, t$ stand for area (rural, urban) and time (1963-64-1993-94). The results of the regression are given in Table 6 where coefficients are based on OLS but $t$-values are corrected for autocorrelation. The income elasticity of inequality is positive for all samples-i.e., rural, urban, pooled and weighted samples, and it is four times higher in the rural areas than in the urban areas; however, it is significant at 5 percent level only for the rural areas and for the weighted sample. A one percent increase in average household income results in an increase in the Gini coefficient by 0.049 percent in the rural areas and about 0.037 in the weighted sample. It turns out that the explanatory power of average household income for determination of inequality is in the range of 30 to 35 percent which is very low.

Table 6

Regression of Inequality on Growth

\begin{tabular}{|c|c|c|c|c|}
\hline & \multicolumn{4}{|c|}{$\begin{array}{c}\text { Dependent Variable: Log (Gini) } \\
\text { Independent Variable: Log (Average Household Income) }\end{array}$} \\
\hline & $\overline{\text { Rural }}$ & Urban & National Pooled & National Weighted \\
\hline$\overline{d_{0}}$ & -1.43 & -1.11 & -1.33 & -1.26 \\
\hline & $(-11.619)$ & $(-6.922)$ & $(-8.09)$ & $(-9.349)$ \\
\hline$d_{1}$ & 0.049 & $0.019 *$ & $0.04 *$ & 0.037 \\
\hline & (3.254) & $(1.653)$ & (1.414) & $(3.022)$ \\
\hline Adj. $R^{2}$ & 0.36 & 0.12 & 0.23 & 0.33 \\
\hline D.W. & 2.17 & 1.66 & 1.95 & 1.51 \\
\hline $\mathrm{F}$ & 6.98 & 3.62 & 13.2 & 12.63 \\
\hline$\rho$ & 0.13 & 0.55 & 0.62 & 0.5 \\
\hline
\end{tabular}

${ }^{4}$ In a different paper that is in progress the relationship between inequality and growth is being examined postulating a non-linear relationship such as the inverted-U hypothesis of Kuznets. This will require testing the validity of Kuznets hypothesis in our data. Pakistan provides an interesting case for this, as inequality and growth trends have sometimes reinforced each other and sometimes countered each other in all possible permutations. Unlike the data on poverty the data on inequality does not portray any structural shift. 
It seems that the statistical insignificance of the relationship at the urban level is influencing the results in the pooled sample, whereas in the weighted sample significance is achieved due to aggregation as well as due to higher weight of the rural sample in the total. Taking the data in the first difference form (not reported here) it changes the interpretation of the variables but improves the coefficient of determination as well as the magnitudes of individual coefficients but the autocorrelation of errors persists.

The above estimates of $d_{1}$ show the overall income elasticity of inequality that contains the direct effect of income on inequality as well as the indirect effect via the impact of income on poverty and hence inequality. This will serve a useful purpose in a latter section when we try to separate out the effects of income and inequality on poverty. One of the reasons to study how inequality is affected by arise in income is to see how the inequality in turn contributes indirectly to poverty. Use of Gini coefficient as proxy for inequality is made only for convenience, otherwise the Thile index, which is more sensitive to lower income tail as well as decomposable, is a better choice for this task. We have data on Thile index (not reported here) only for total Pakistan (i.e., for the weighted sample). Results obtained from regressing the Thile index on average household income (in the weighted sample) has a coefficient of determination (0.71) and shows a higher responsiveness (elasticity 0.107 ) of Thile index than the responsiveness of Gini coefficient (elasticity .037) to a change in average household income in the same sample. This points to the possibility that growth in income is worsening the distribution more at the lower end than at the middle.

\section{INTERACTION BETWEEN POVERTY, INEQUALITY AND GROWTH}

We would now like to find the long-run decomposition of change in poverty between that due to growth and that due to change in income distribution. This can be achieved through obtaining partial correlation coefficients. Table 7 shows multiple regression of the log of Household Count on $\log$ of Gini coefficient and the log of Average Household Income for rural, urban, pooled, and weighted data. It shows that one percent increase in income while keeping the distribution constant reduces poverty equally in the rural and the urban areas to the tune of 0.31 to 0.32 of that one percent. An increase in Gini coefficient while holding the income constant tends to increase poverty in the pooled as well as in rural urban split samples, such that it creates proportionally more poor households in the urban areas (elasticity 1.58) than in the rural areas (elasticity 0.89). 
Table 7

Regression of Poverty on Inequality and Growth

Dependent Variable: $\ln \mathrm{HHC}$

Independent Variables: $\ln \mathrm{GINI}_{a, t}, \ln A H H I_{a, t}$ $\ln H H C_{a, t}=h_{0}+h_{1} \ln G I N I_{a, t}+h_{2} \ln A H H I_{a, t}+h_{a}+\gamma$

Rural Urban National National

\begin{tabular}{lcccc}
\hline$h_{0}+h_{a}$ & 6.46 & 7.0 & 5.42 & 7.16 \\
& $(4.37)$ & $(11.55)$ & $(9.67)$ & $(9.08)$ \\
$h_{1}$ & 0.89 & 1.58 & $0.123^{*}$ & 1.67 \\
& $(2.36)$ & $(2.98)$ & $(0.75)$ & $(4.04)$ \\
$h_{2}$ & -0.31 & -0.32 & -0.29 & -0.32 \\
& $(-3.98)$ & $(-14.02)$ & $(-5.71)$ & $(-7.94)$ \\
Adj. ${ }^{2}$ & 0.87 & 0.94 & 0.87 & 0.92 \\
D.W. & 1.14 & 1.7 & 1.3 & 1.87 \\
$F$-statistic & 29 & 104 & 60.9 & 53.5 \\
$\rho$ & & & 0.64 & \\
\hline
\end{tabular}

Notes: 1. The coefficients are based on OLS estimation while the $t$-values are in parenthesis, which are based on robust standard errors after correcting for auto-correlation using AR(1) CochraneOrcutt iterative procedure.

2. Coefficients not significant at 5 percent level are marked with an asterisk $(*)$.

3. Adjusted $\mathrm{R}^{2}$ is based on original OLS method, while $F$-Statistic is that after correction for autocorrelation.

4. $\rho$ estimate of auto-correlation coefficient in errors

\section{CONCLUSION}

The paper contributes to the existing literature on poverty, and particularly on the analysis of Pakistan's poverty situation in at least the following four ways:

1. It develops three consistent time series on rural, urban, and total poverty (both at household level and at individual level, which, in fact, makes them six series) that covers all Household Expenditure Surveys that have been conducted so far, thus providing the longest such series developed for Pakistan. Consistency is achieved by defining rural and urban poverty lines separately and then maintaining to use the same poverty lines (of course adjusted for inflation over time) for all survey years, and by using the same method of calculation for each year. This provides a good data for analysis of poverty and the related issues. Of course other sources of inconsistencies such as those due to differences in the quality of surveys etc., are not corrected in the series, but they are taken care of in making use of these series. 
2. It highlights the econometric problems in using the survey data in conjunction with aggregate data on poverty and income to derive the conclusions. It then shows a proper way and applies the method on Pakistan's data.

3. The relation between growth and poverty, in the context of developing countries, has so far been possible only with cross country data [Ravallion and Chen (1997)] due to lack of availability of long time series on the relevant variables (except for a recent study by Wodon (1999) on Bangladesh with panel data but which is limited to data from few years). Our study makes an analysis of the relationship between poverty and growth, between inequality and growth, and interaction between these three variables in the context of a single developing country. It thus avoids the problems of country specific effects that plague the cross sectional data in obtaining a general relation between these variables.

4. The study provides a conceptual framework for the analysis of growth, poverty and inequality arguing that the non-linearity in the relationships between these variables in the short-run and the institutional factors behind the process of poverty alleviation, that change only slowly, require knowledge of long-run relationships. The study provides long-run elasticities of poverty with respect to growth and inequality which are useful for policy purposes.

Some policy conclusions that are obtained from this systematic analysis are that Growth, Itextit \{ceteris peribus, \} has always helped in poverty reduction. Growth has worsened income inequality at the national level but more so in the rural areas. Increase in inequality, keeping growth unchanged, has contributed to rise in poverty more in the urban areas than in the rural areas. Overall the dominant effect of growth has been of poverty reduction. Therefore, to address poverty reduction in the rural areas growth oriented policies must be accompanied by measures of inequality reduction, because growth induces inequality there. In the urban areas growth is much more important, and inequality reduction policies are needed for reasons other than growth induced inequality.

\section{REFERENCES}

Ahmad, M. (1993) Choice of a Norm of Poverty Threshold and Extent of Poverty in Pakistan. Ministry of Finance, Islamabad. (Mimeographed.)

Alesina, Alberto, and Dani Rodrik (1994) Distributive Politics and Economic Growth. Quarterly Journal of Economics 108: 465-90.

Ali, Mohammad S. (1997) Poverty Alleviation: The Existing Situation. In Mohibul Haq Sahibzada (ed.) Poverty Alleviation in Pakistan. Islamabad: Institute of Policy Studies. 93-114. 
Allaudin, T. (1975) Mass Poverty in Pakistan: A Further Study. The Pakistan Development Review 14:4.

Amjad, R., and A. R. Kemal (1997) Macroeconomic Policies and their Impact on Poverty Alleviation in Pakistan. The Pakistan Development Review 36:1 39-68.

Datt, Gaurav, and Martin Ravallion (1992) Growth and Redistribution Components of Changes in Poverty Measures: A Decomposition Analysis with Application to Brazil and India in the 1980s. Journal of Development Economics 38:2 275-295.

de Kruijk, H., and M. van Leeuwen (1985) Changes in Poverty and Income Inequality in Pakistan during the 1970s. The Pakistan Development Review 24:3\&4 407-19.

Gazdar, H., S. Howes, and S. Zaidi (1994) Pakistan: Recent Trends in Poverty. Background Paper for Pakistan Poverty Assessment. World Bank, Islamabad. (Mimeographed.)

Greene, William H. (1997) Econometric Analysis, 3rd Edition. New Jersey: PrenticeHall.

Gujarati, Damodar N. (1995) Basic Econometrics, 3rd Edition. Singapore: McGrawHill.

Jafri, S. M. Younus (1999) Assessing Poverty in Pakistan. In A Profile of Poverty in Pakistan. Islamabad: Mahbubul Haq Centre for Human Development and UNDP.

Kakwani, Nanak (1993) Poverty and Economic Growth with Application to Cote d'Ivorie. Review of Income and Wealth 39: 121-139.

Kanbur, S. M. Ravi (1987) Structural Adjustment, Macroeconomic Adjustment and Poverty: A Methodology for Analysis. World Development 15:12 1515-1526.

Kuznets, S. (1955) Economic Growth and Income Inequality. American Economic Review 45:1 1-28.

Mahmood, Moazzam (1999) Macro Explanations of Poverty. In A Profile of Poverty in Pakistan. Islamabad: Mahbubul Haq Centre for Human Development and UNDP.

Mahmood, Z. (1984) Inequality in Pakistan: An Analysis of Existing Evidence. The Pakistan Development Review 23:2\&3 365-76.

Malik, Mohammad H. (1988) Some New Evidence on the Incidence of Poverty in Pakistan. The Pakistan Development Review 27:4 509-15.

Malik, S. J. (1996) Determinants of Rural Poverty in Pakistan: A Micro Study. The Pakistan Development Review 35:2 171-87.

Mujahid, G. B. S. (1978) A Note on Measurement of Poverty and Income Inequalities in Pakistan: Some Observations on Methodology. The Pakistan Development Review 17:3.

Naseem, S. M. (1977) Rural Poverty and Landlessness in Pakistan. In Poverty and Landlessness in Asia. Geneva: ILO.

Naseem, S. Mohammad (1973) Mass Poverty in Pakistan: Some Preliminary Findings. The Pakistan Development Review 12:4. 
Naseem, S. Mohammad (1996) The Informal Sector and Urban Poverty Alleviation in Pakistan. In ESCAP: Role of the Informal Sector in Poverty Alleviation. New York: United Nations.

Pakistan, Government of (Various Issues) Household Income and Expenditure Surveys for the years 1963-64, 1966-67, 1968-69, 1969-70, 1970-71, 1979, 198485, 1985-86, 1986-87, 1987-88, 1990-91, 1992-93, 1993-94. Karachi: Federal Bureau of Statistics.

Pakistan, Government of (Various Issues) Pakistan Economic Surveys. Islamabad: Economic Advisor's Wing, Ministry of Finance.

Ravallion, Martin, and Shaohua Chen (1997) What Can New Survey Data Tell Us about Recent Changes in Distribution and Poverty? World Bank Economic Review 11:2 357-82.

Shirazi, N. S. (1995) Determinants of Poverty in Pakistan. Pakistan Economic and Social Review 33:1\&2 91-101.

Tahir, Sayyid, and Salman Syed Ali (1999) Growth with Equity: Policy Lessons from Experience of Pakistan. In Growth with Equity. Bangkok: ESCAP, UN.

Wodon, Quentin T. (1999) Growth, Poverty and Inequality: A Regional Panel for Bangladesh. The World Bank, South Asia Region, March. (Policy Research Working Paper 2072.)

World Bank (1990) World Development Report. New York: Oxford University Press.

World Bank (1995) Pakistan Poverty Assessment. Washington D.C.: The World Bank, September. (Report No. 14397-PAK.)

World Bank (1998) Annual World Bank Conference on Development Economics 1998. Washington, D. C.: World Bank. 


\section{Comments}

A number of studies have been undertaken during the last three decades to assess the extent and nature of poverty in Pakistan. These studies are primarily based on the data generated by the Household Income and Expenditure Surveys (HIES). Most of the studies have dealt with few survey years and used a different methodology. These studies are not strictly comparable. Even then it has been common to use these methodologically different studies to determine the trends in poverty in Pakistan. Ali and Tahir's paper has made a significant contribution in the existing literature on poverty by calculating consistent time series for poverty dividing into rural and urban sectors as well as the aggregate of the two.

The authors have used the primary data sets of 14 Household Income and Expenditure Surveys, from 1963-64 to 1993-94. The paper did not define a new poverty threshold, rather it used the income poverty line defined by Malik (1988) as a bench mark and adjusted it according to inflation. For inequality measure, the paper relies on the data provided by Mahmood (1984) and Pakistan Economic Survey. By using these data, the authors examined the relationship between poverty and growth, between inequality and growth, and interaction between these three variables.

The paper provides good data for analysis of poverty and related issues. The authors' have developed the time series for poverty by using several primary data sets. My general comments on the paper are following:

First, interestingly results of Ali and Tahir's study are similar to the outcomes of previous studies based on different methodologies and poverty lines. It is well established that in the 1960s rural poverty increased while urban poverty decreased. In the next decade poverty declined at all levels. This declining trend continued until 1987-88. Ali and Tahir's time series on poverty is in consistent with the results of the previous studies based on different methodologies. Why is it so?

Second, no real consensus could emerge on the trends in poverty in the 1990s. Gazdar (1994) and Jafri (1999), for example, show that decline in poverty continued in the early 1990s. Amjad and Kemal (1997), on the other hand, have shown an increase in poverty during this period. Ali and Tahir's paper confirms the findings of Amjad and Kemal. This confirmation is understandable since the two studies have used a similar approach. It would have been useful if the authors had compared their results with that of Gazdar (1994) and Jafri (1999).

Third, results of the present study have shown a decline in poverty between 1992-93 and 1993-94. This decline is particularly substantial in urban areas, about 2

percent. However, it is difficult to explain it through macro-level factors such as 
employment, real wage rates, workers' remittances and inflation. The authors should give some explanations of this decline.

Fourth, with respect to time series on distribution statistics, results for 199394 are confusing. Table 5 (column 4) shows that income share of highest 20 percent declined by 8 percent just in one year. An increase of 5 and 3 percent was shown in the income share of 60 percent middle households and 20 percent lowest households respectively. This is the largest increase/decrease in a single year. It needs some explanation. In my opinion, there seems to be some problem in the 1993-94 HIES data sets. The authors should look into this again more carefully.

Pakistan Institute of Development Economics,

G. M. Arif

Islamabad. 